\title{
Editorial
}

\section{Empresas y entornos sociales}

\author{
Por Carlos Duarte*
}

$\mathrm{L}$ as empresas son quizás una de las más extendidas formas de organización social de la actualidad. Como bien sabemos, estas responden a una particular manera de formalizar la contradicción clásica entre capital y trabajo, respondiendo a diversas necesidades del mercado o de una comunidad. Estas, además de responder a una función económica, están formadas por personas y para personas, lo que significa que se encuentran circunscritas a los contextos sociales que las originan. Las empresas están incrustadas en las sociedades y no pueden subsistir al margen de estas. Históricamente, las empresas - como representantes del sector privado en Colombia- han tenido un rol fundamental en la construcción de nuestro Estado-nación; pero, a su vez, en un contexto de neoliberalización económica y reducción de la capacidad estatal, han venido ganando un papel hegemónico en las orientaciones políticas y en los modelos de desarrollo que se han priorizado a nivel nacional y regional.

A pesar de su importancia, nuestra capacidad para pensar las empresas parece más bien limitada. Por una parte, los debates parecen remitirse a reflexiones apologéticas y narrativas institucionales, que en el mejor de los casos desembocan en los modernos discursos de sostenibilidad empresarial. Por otra parte, los ejercicios analíticos realizados desde las ciencias sociales caen fácilmente en posiciones binarias que tienden a estigmatizar de facto el rol empresarial en cualquier contexto en el que se mencione.

* Profesor del Instituto de Estudios Interculturales - IEI. Pontificia Universidad Javeriana de Cali. 
Por lo anterior, la presente convocatoria de la edición 212 de la Revista Controversia invitó a reflexionar en torno a los diferentes modelos empresariales que conviven, compiten, dinamizan y entran en conflicto con diversos sectores de la sociedad colombiana, especialmente los de su entorno. En términos generales, se buscó comprender los vínculos y las tensiones entre el sector privado empresarial y las diversas comunidades, especialmente rurales.

En este contexto, recibimos diferentes aportes que podrían describirse en dos grandes grupos de artículos: de una parte, contribuciones que se encargan de pensar contextos nacionales e internacionales; y de otra, análisis de estudios de caso.

Con referencia al primer grupo, nos encontramos con un bloque de tres textos que comienzan con el estudio de la Responsabilidad Social Empresarial como herramienta para la gestión de conflictos con comunidades rurales. Este es un texto construido a tres voces por Manuel Ramiro Muñoz, Daniela Díaz Lozano y María Alejandra Quintero Falla. Posteriormente, Piedad Andrea Rodríguez, Daniela Alejandra Gómez y Daniela Caicedo se ocupan de analizar la relación entre la Consulta Previa y los Principios Ruggie, tema profundamente estratégico para el tríptico constituido entre empresas, Estado y comunidades. Como último aporte de este primer conjunto de textos, el lector volverá al tema empresarial y de derechos humanos, pero desde la óptica particular que define el enfoque diferencial e intercultural a cargo de Luisa Fernanda Duque Muñoz, Laura Álvarez Tobar y María Jimena Fernández Merchán.

El segundo grupo de contribuciones, que se concentró en analizar estudios de caso, comienza con el artículo de Germán Torres, en torno a las dinámicas de concentración y acumulación de la tierra en Colombia, en el caso de la agroindustria de caña de azúcar. Posteriormente, el lector se encontrará con un par de trabajos que se especializan en las industrias minero-energéticas. Así, en primer lugar, está el artículo de Karla 
Díaz acerca del Petróleo y la inseguridad jurídica en la tenencia de la tierra en el Caquetá. Y finalmente, pero no menos importante, el lector descubrirá el artículo de Julie Paola Tibocha Avellaneda, quien relaciona el poder de agenciamiento de la movilización social como freno a la locomotora minera, para el caso del páramo de Santurbán. 